\title{
In vitro and in vivo activities of flavonoids - apigenin, baicalin, chrysin, scutellarin - in regulation of hypertension - a review for their possible effects in pregnancy-induced hypertension
}

\author{
MARCIN OŻAROWSKI ${ }^{1 \star}$, RADOSŁAW KUJAWSKI ${ }^{2}$, PRZEMYSŁAW Ł. MIKOŁAJCZAK ${ }^{1,2}$, \\ KAROLINA WIELGUS ${ }^{1}$, ANDRZEJ KLEJEWSKI ${ }^{3,4}$, HUBERT WOLSKI ${ }^{5,6}$, AGNIESZKA SEREMAK- \\ MROZIKIEWICZ ${ }^{1,5,7}$
}

\author{
${ }^{1}$ Institute of Natural Fibres and Medicinal Plants \\ Wojska Polskiego 71b \\ 60-630 Poznań, Poland \\ ${ }^{2}$ Department of Pharmacology \\ Poznań University of Medical Sciences \\ Rokietnicka 5a \\ 60-806 Poznań, Poland \\ ${ }^{3}$ Department of Nursing \\ Poznań University of Medical Sciences \\ Smoluchowskiego 11 \\ 60-179 Poznań, Poland \\ ${ }^{4}$ Department of Obstetrics and Women's Diseases \\ Poznań University of Medical Sciences, \\ Smoluchowskiego 11 \\ 60-179 Poznań, Poland \\ ${ }^{5}$ Department of Perinatology and Women's Diseases \\ Poznań University of Medical Sciences \\ Polna 33 \\ 60-535 Poznań, Poland \\ ${ }^{6}$ Division of Gynecology and Obstetrics \\ Podhale Multidisciplinary Hospital \\ Nowy Targ, Poland \\ ${ }^{7}$ Laboratory of Molecular Biology
}


Poznań University of Medical Sciences

Polna 33

60-535 Poznań, Poland

* corresponding author: e-mail: marcin.ozarowski@iwnirz.pl

\section{Summary}

Flavonoids and their conjugates are the most important group of natural chemical compounds in drug discovery and development. The search for pharmacological activity and new mechanisms of activity of these chemical compounds, which may inhibit mediators of inflammation and influence the structure and function of endothelial cells, can be an interesting pharmacological strategy for the prevention and adjunctive treatments of hypertension, especially induced by pregnancy. Because cardiovascular diseases have multifactorial pathogenesis these natural chemical compounds with wide spectrum of biological activities are the most interesting source of new drugs. Extracts from one of the most popular plant used in Traditional Chinese Medicine, Scutellaria baicalensis Georgi could be a very interesting source of flavonoids because of its exact content in quercetin, apigenin, chrysin and scutellarin as well as in baicalin. These flavonoids exert vasoprotective properties and many activities such as: anti-oxidative via several pathways, anti-inflammatory, anti-ischaemic, cardioprotective and anti-hypertensive. However, there is lack of summaries of results of studies in context of potential and future application of flavonoids with determined composition and activity. Our review aims to provide a literature survey of in vitro, in vivo and ex vivo pharmacological studies of selected flavonoids (apigenin, chrysin and scutellarin, baicalin) in various models of hypertension carried out in 2008-2018.

Key words: flavonoids, pharmacological activity, in vitro models, animal models, hypertension, pregnancy-induced hypertension

Słowa kluczowe: flawonoidy, aktywność farmakologiczna, modele in vitro, modele zwierzęce, nadciśnienie, nadciśnienie indukowane ciąża

\section{INTRODUCTION}

Flavonoids and their conjugates are a very large group of natural chemical compounds. The analysis of these metabolites is one of the most important areas in the field of drug discovery and development. These natural chemical compounds show a wide spectrum of biological activities and among others they can play in prevention and treatment of multifactorial cardiovascular diseases. The activity of certain flavonoids on vascular dysfunction has been the subject of many studies and reviews, since 1959 [1]. Recently, attention has been paid to natural chemical compounds in order to the discovery of new antihypertensive therapeutics especially as drug candidates in prevention and treatment of hypertension [2]. Among the active plant phenolics the most interesting are quercetin, apigenin, chrysin and scutellarin, baicalin occurring in the various extracts from Scutellaria sp. [3-7].
One of important medical and therapeutic problems is hypertension induced by pregnancy (PIH) [2]. According to review by Ożarowski et al. [2], hypertensive disorders diagnosed during pregnancy were classified as: (1) chronic hypertension, (2) preeclampsiaeclampsia, (3) preeclampsia superimposed on chronic hypertension, (4) gestational hypertension (transient hypertension of pregnancy or chronic hypertension identified in the latter half of pregnancy). PIH may lead to functional and structural complications, i.e. placental abruption, elevated levels of liver enzymes, hemolysis, renal failure, cerebral vascular accidents [8]. As it was described previously $[2,9,10]$ "preeclampsia is was defined as high blood pressure ( $\geq 140 \mathrm{mmHg}$ systolic or $\geq 90 \mathrm{mmHg}$ diastolic, or increases of $30 \mathrm{mmHg}$ systolic or $15 \mathrm{mmHg}$ diastolic from the baseline on at least two occasions, six or more hours apart) that develops from the $20^{\text {th }}$ gestational week in a previously normotensive woman, with proteinuria (one 24-hour urine collection with a total protein excretion of at 
least $300 \mathrm{mg} / \mathrm{l})$ ". The main pathological basis is damage of endothelial cells, followed by dysfunction of vasoactive, inflammatory and clotting factors. Furthermore, an oxygenation plays a key role in the course of pathogenesis in preeclampsia.

Hence, there is a possibility of intervention with the use of flavonoids as dietary components or herbal medicinal drugs. Presented review is a summary of recent results on activity of selected flavonoids in pharmacological models in vascular disorders, especially in hypertension, taking into account pregnancy-induced hypertension.

\section{APIGENIN}

\section{Natural source and pharmacological profile}

A 4‘,5,7-trihydroxyflavone (fig. 1), called apigenin, is a flavonoid common in vegetables, fruits or plants with medical properties, i.e. in Petroselinum crispum Mill.) Fuss. (parsley, Apiaceae) and Matricaria chamomilla L. (chamomile, Asteraceae) [11, 12] or celery seeds (Apium graveolens L. (Apiaceae)) [13, 14]. Biological properties of the compound with its influence of cardiovascular system were summarized by Wang et al. [15], Zhou et al. [14] and Ali et al. [16].

Currently, there is an increasing interest in prohealth and healing properties of apigenin due to its proved relatively low toxicity on non-affected cells and its effectiveness on cells with altered biochemistry, which is particularly evident in the case of cancer cells [17]. Results of growing number of studies underlines apigenin's strong therapeutic potential against a number of diseases $[14,16]$. Particularly noteworthy is the increasing number of data indicating the properties of apigenin, which may be helpful in the prevention or inhibition of symptoms manifested as a hypertension developed during pregnancy.

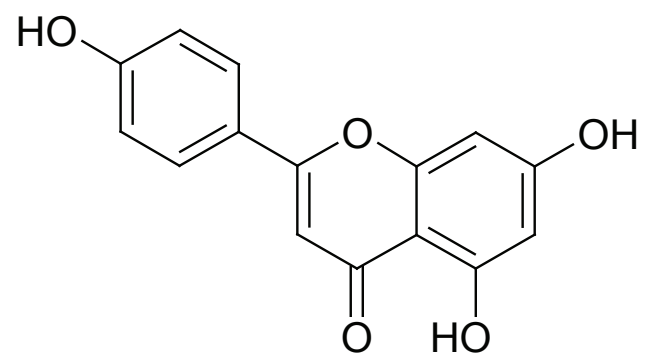

Figure 1

Chemical structure of apigenin (ISIS Draw).

\section{In vitro and ex vivo results of apigenin's influence on the causes of hypertension Vasodilatation}

In early 90's [18], the in vitro vasodilatory effect of apigenin on rat thoracic aorta rings isolated from the extract from A. graveolens (celery) seeds was observed, which, as it has been postulated, could act via inhibition of the $\mathrm{Ca}^{2+}$ influx via ligand and/or voltagegated calcium channels. In this study, this compound inhibited the contraction of aortic rings caused by cumulative concentrations of calcium (0.03-3 mM) $\left(\mathrm{IC}_{50}=\mathrm{ca} 48 \mu \mathrm{M}\right)$ [18]. Promising results were also obtained in rats aorta rings ex-vivo (via influence on the $\mathrm{Ca}^{2+}$ influx into cells or the extrication of $\mathrm{Ca}^{2+}$ from smooth muscles sarcoplasma) in the case of hexane extract, however, the observed properties were attributed primarily to its another active component n-butylphthalide (NBP) [13]. In another, similar study in dissected endothelium-stripped thoracic aortic rings from male Sprague-Dawley rats pretreated with phenylephrine, apigenin $(0.5-72 \mu \mathrm{M})$ caused vasorelaxation (the $\mathrm{E}_{\max }=28.7 \% \pm 7.3 \%$ ) and attenuated decreased endothelium-dependent vasorelaxation triggered by pyrogallol (with relaxation at maximum level from $55.8 \% \pm 6.6 \%$ to $69.5 \% \pm 6.4 \%$, respectively) [19]. It has resulted in quantitative indications of oxidative stress and nitric oxide turnover, mainly it elevated the superoxide anion suppression process (from $94.6 \%$ to $74.5 \%$ ), the nitric oxide level, and the constitutive nitric oxide synthase activity [19]. Another one comparative analysis of vasodilatory effect of the subfractions isolated from the Ziziphora clinopodioides Lam. (Lamiaceae) hydroalcoholic extract (in Uighur's medicine commonly used against hypertension symptoms) containing apigenin and other phenolic compounds (acetovanillone, thymonin, chrysin, acacetin, 4-hydroxyacetophenone, ethyl 4-coumarate) was carried out in isolated rat thoracic aortic rings, as a result of which the highest potential of the isolated apigenin and other two flavones (ethyl 4-coumarate, chrysin) was observed [20].

\section{In vivo studies related to the various models of hypertension}

In comparative study by Tashakori-Sabzevar et al. [13], in which especially the hexanic extract of A. graveolens seed strongly decreased four heart pressure parameters, such as: the diastolic (DBP), systolic (SBP), mean arterial blood pressure (MABP), and 
heart rate (HR) after intravenous injection. They found that hexanic extract and nifedipine (a positive control) similarly lowered diastolic and systolic heart pressure, and mean arterial value in rats with normal and hypertension, while taking into account the HR parameter - in the case of hexanic extract an induction of bradycardia was observed. They postulated that the presence of this nonpolar flavonoid, as well as another two compounds - sedanenolide and sedanolide could contribute to these effects. Exactly which one of these compounds the kind of effect caused - this type of analysis was not carried out in abovementioned experiment. Tang et al. investigated the vasodilatory mechanism of fresh juice from A. graveolens and the results obtained prompted the research team to suggest that it might act as inhibitor of the receptor-operated channel (ROC) in the smooth muscles [21]. It is in relation with another study in which it was shown that a peripheral vascular resistance may significantly influence on the DBP; therefore, A. graveolens extract from seeds gave vasorelaxant effects, which could be due to NBP, observable concentrations of apigenin, d-limonene, linalool and/or other similar substances. In a study on the $\mathrm{N}$-nitro-L-arginine methyl ester hydrochloride (L-NAME) (nitric oxide-deficient) hypertensive rats [22] it was found that apigenin, among other compounds, significantly reduced their elevated blood pressure that is related with the chronic deficiency of NO. Other study by Paredes et al. [23] also revealed vasorelaxative properties of apigenin in different strain of rats - SHR (spontaneously hypertensive rats) animals, in which after administration with this flavone for 6 (SHR6 group) or 12 weeks (SHR12 group) a correction of relaxation of the aortic blood vessels and elevated plasma and urinary nitrites excretion was detected as well as the reduction of excretion of the urinary thiobarbituric acid reactive substances (TBARS) and proteinuria. In the SHR6 group administration with apigenin led to moderate improvement of pathologically changed vascular lumen/wall ratio in heart arteries and thoracic aorta [23]. Other study performed on 12 weeks aged SHR showed that apigenin $(0.007$, $0.026,0.104$ and $0.417 \mathrm{~g} / \mathrm{kg}$ ) lowered systolic blood pressure related to up-regulation the expression of mRNA ACE2 in kidney [24]. The improvement of hypertensive cardiac hypertrophy and glycolipid metabolism in abnormal heart muscle due to apgenin's treatment seemed, as authors concluded, to take place according to influence on expression of genes regulating glycolytic and glycerol-lipid biosynthesis, shifting of cardiac metabolism mediated by hypoxia-inducible factor $1 \alpha$ (HIF- $1 \alpha)$, peroxisome proliferator-activated receptor $\alpha, \gamma(\operatorname{PPAR} \alpha, \gamma)$ [25]. It decreased of myocardial HIF- $1 \alpha$ transcription, up-regulated the expressions of myocardial PPAR $\alpha$ and its target genes: carnitine palmitoyltransferase (CPT-1), pyruvate dehydrogenase kinase (PDK4), down-regulated of myocardial PPAR $y$ and its target genes: glycerol-3-phosphate acyltransferase (GPAT), GLUT-4 (on mRNA and protein level) expression [26]. Furthermore, this flavone applied as a diet, revealed also a preventive property on hypertension-induced renal fibrosis in male hypertensive Sprague-Dawley rats induced by deoxycorticosterone acetate (DOCA) - salt agonized the activity of transient receptor potential vanilloid 4 (TRPV4) in both, the kidney and renal cells, strongly weaken the DOCA-salt-induced damage of kidneys structure and function, with simultaneous down-regulation of transforming growth factor- $\beta 1$ (TGF- $\beta 1$ )/ Smad2/3 signal transduction route, AMP-activated protein kinase (AMPK)/sirtuin 1 (SIRT1) cascade and extracellular matrix proteins expression [27].

Results by Zhang et al. provided evidences for regulatory activity of apigenin on cholesterol metabolism in vivo (administered p.o. in hypercholesterolemic ICR mice once per day through 28 consecutive days) causing the significant, dose-dependent lowering concentrations of low-density lipoprotein cholesterol (LDL-C), triglycerides (TG) and total content of cholesterol (TC) in their serum, consequently reducing their total body mass. Authors attempted to evaluate the molecular mechanism of action of apigenin's ability to decrease the concentration of fat in blood of studied animals. For this purpose, liver's transcription levels changes of three genes encoding enzymes limiting the cholesterol metabolism, such as: cytochrome P450 type 7 (CYP7A1 - catalyzing cholesterol transformation into bile acid [29]), LDL$\mathrm{R}$ (receptor crucial for mediating of LDL-C uptake in liver) [30], and 3-hydroxy-3-methyl-glutarylcoenzyme A reductase (HMG-CoAR: crucial in cholesterol synthesis rate) were quantified, all of which were substantially down-regulated in a high-fat diet animals. Above mentioned flavonoid significantly stimulated the expression of mRNAs for CYP7A1 in animals administered with its higher dose, while in both groups of mice (high and low-dosage ones) the number LDL-R transcripts were also elevated in a significant manner [28]. Furthemore, in EA.hy926 (macrophage-derived foam) cells it also dose-dependently stimulated the superoxide dismutase (SOD) and decreased the degree of proliferation of vascular smooth muscle cells as well [28]. 


\section{Influence in pregnancy}

One of interesting studies is the research by Lim et al. [31], prone to penetration of apigenin through placenta cells, suggesting that this polyphenol, as well as two other ones studied (curcumin, naringenin) were able to reduce infection, mediators promoting labour-induced experimental inflammation state (LPStreatment) in human placenta tissue extracts such as human amnion epithelial cells (extracted from foetal membranes) and human uterine smooth muscle cells (derived from human pregnant myometrium) and influenced on oxidative stress markers (being considered as a promoting of several pregnancy-related disorders promoting process, i.e. pre-eclampsia, or preterm labour [32, 33]). Obtained results defined their actions to the modulation of NF- $\mathrm{kB}$ signaling pathway playing an important role in human labour and delivery [31]. Apigenin (5 and $20 \mu \mathrm{M}$ ) significantly slowed down the IL-6 secretion, previously stimulated by the lipopolysaccharide (LPS) treatment. Its $20 \mu \mathrm{M}$ concentration significantly down-regulated the level of LPS-induced IL-6 and IL-8 transcripts in human placenta, foetal membranes and myometrium cells, thus strongly inhibited LPS-stimulated these cytokines secretion, with no effect on the IL- $1 \beta$-induced encoding gene transcription and release. Furthermore, it strongly lowered the level of LPS-induced COX-2 transcripts and attenuated its secretion. For the PGF2a release results of apigenin action were similar. In placenta, apigenin did not influence the MMP9 mRNA, previously induced by LPS, moreover it attenuated increased by LPS pro-MMP-9 activity, and down-regulated the IL-1 $\beta$-stimulated MMP-9 encoding gene transcription. However, in IL- $1 \beta$ stimulated myometrial cells the level MMP-9 transcripts was lowered after the treatment with apigenin with no influence on this IL- $1 \beta$-induced active metalloproteinase activity [31]. Bearing in mind the fact that oxidative stress may play important, causative role in the processes related with preterm, premature rupture of the membranes (PPROM) [34, 35] prompted authors for the further in-depth examination of this issue. For this purpose the study aiming the influence of this polyphenol on an example of lipid peroxidation marker, such as 8-isoprostane, was conducted, which showed an attenuation of LPS-induced 8-isoprostane secretion in placenta tissue (no potential changes could be detected using the technique in myometrial cells) [36]. Authors concluded that this flavonoid can act as a potent antioxidant leading to the lowering of pro-labour mediators. The effect of this flavone on pro-inflammatory cytokines, prostaglandins and above mentioned metalloproteinase in human gestational tissues suggests its involvement in modulating of events promoting rupture of membranes and PPROM and myometrial contractions. Even more, in placenta in foetal membranes apigenin reduced also LPS-stimulated NF- $\kappa B$ p65 DNA-binding activity. The abovementioned results, along with the results of study by Nicholas et al. [37], proving that apigenin is capable to inhibit NF- $\mathrm{kB}$, clearly indicate its properties against inflammation in human gestational tissues via the NF- $\kappa B$ pathway. According to Lim et al. [31] besides the obvious beneficial antioxidant and anti-inflammatory actions of apigenin (and two other polyphenols), there is a growing number of information about their toxicity [38], which, according to the authors, together with their multidirectional mechanism of action speaks for a significant extent for the possibility of using their potential application in pregnancy-induced hypertension.

\section{BAICALIN}

\section{Natural source and pharmacological profile}

Baicalin (5,6-dihydroxy-7-O-glucuronide flavone) (fig. 2a, 2b) is a predominant flavone glycoside occurring in roots of Scutellaria baicalensis Georgi (Huang Qin) [3,39], and also naturally occurring flavonoid in other plants of Scutellaria such as S. lateriflora L. [40], S. barbata D. Don [41], S. galericulata L. [4], S. amoena, S. viscidula [7]. Baicalin has been widely studied in several in vitro and in vivo models and showed many activities such as: anti-viral [42], anti-oxidative via several pathways [43], neuroprotective and enhancin cognitive functions [44, 45], anti-inflammatory [46], anti-cancer [47, 48], and hepatoprotection [49]. In recent years, many studies showed anti-hypertensive properties of baicalin [46, 50-60], and also cardioprotective [50], antiplatelet, anticoagulant, and profibrinolytic activities [61].

\section{In vitro and ex vivo studies related to the causes of hypertension Vasodilatation}

Lin et al. [59] showed that baicalin at 30 and $100 \mu \mathrm{M}$ alleviated $\mathrm{KCl}$-induced contraction in a dose dependent manner in isolated rat mesenteric artery. 
The mechanism of induced relaxation after administration of baicalin may involve activation of largeconductance $\mathrm{Ca}^{2+}$-activated $\mathrm{K}^{+}(\mathrm{BKCa})$ channels and inhibition of VDCC channels via up-regulating two pathways such as cGMP/PKG and cAMP/PKA.

\section{Renin and ACE inhibitory activities}

It is well known that the renin-angiotensin system is a key regulator in the pathogenesis of hypertension. Deng et al. [58] revealed in vitro that baicalin showed the inhibition of renin activity with an $\mathrm{IC}_{50}$ value of $120.36 \mu \mathrm{M}$ and revealed a low level of inhibition of angiotensin-converting-enzyme (ACE) activity with an $\mathrm{IC}_{50}$ value of $2.24 \mathrm{mM}$. Study of interaction showed that a complex of baicalin - renin was more stable in comparison with complex of baicalin - ACE. These results explain stronger inhibition of renin by baicalin compared to ACE inhibition.

\section{Anti-inflammatory activity}

Dong et al. [62] also studied the anti-inflammatory activity of baicalin $(10,50,100 \mu \mathrm{g} / \mathrm{ml})$ on inflammation caused by lipopolysaccharide (LPS) in HBE16 airway epithelial cells. They observed that this flavonoid in a dose-independent manner inhibited expression of mediators such as IL- 6 , IL-8, and TNF- $\alpha$ via preventing signaling NF- $\kappa \mathrm{B}$ pathway in cell culture. The antiinflammatory activity of baicalin was also found in other cell cultures i.e. human arterial endothelial cells (HAECs) exposed to ischemia reperfusion injury [63], human chondrocyte cell line $\mathrm{CHON}-001$ treated with IL-1 $\beta$ [64], human hepatocyte cell $1 \beta$ e [66], human cervical cancer cell lines HeLa and SiHa [67].

\section{In vivo studies related to the various models of hypertension}

Baicalin is intensively studied in various animal models of hypertension, atherosclerosis and myocardial ischaemic injury, but most studies were carried out only in model of pulmonary hypertension ( $\mathrm{PH})$. Chen and Wang [53] showed in an infant rodent model of $\mathrm{PH}$ that baicalin exerted anti-inflammation activity. It was observed that after oral administration in the doses from $10 \mathrm{mg} / \mathrm{kg} /$ day to $30 \mathrm{mg} / \mathrm{kg} /$ day baicalin significantly attenuated pulmonary arterial pressure, and right ventricular hypertrophy in infant rats. Few biomarkers such as advanced glycation end products, IL 6 , TGF $\beta 1$ in bronchoalveolar lavage fluid (BALF) were also reduced after baicalin treatment [53]. Furthermore, in this study it was shown that HMGB1/RAGE signaling can be taken into account as a molecular point of action for baicalin. Therefore, baicalin is mentioned as anti-inflammatory flavonoid which can play beneficial role in prevention and treatment of infant $\mathrm{PH}$ [53]. Luan et al. [46] observed the protective effects of intragastric administration of baicalin $(100 \mathrm{mg} / \mathrm{kg})$ in rat model of monocrotaline (MCT)-induced PH. After two weeks it was observed the inhibition of vascular endothelial inflammatory response mainly by decreasing of levels of mRNA for several factors such as TNF- $\alpha$, IL- $1 \beta$, IL-6, ET-1, TGF- $\beta 1$, ICAM-1, NF- $\kappa$ B. Moreover, baicalin caused reducing right ventricular hypertrophy, and attenuating pulmonary vascular remodelling. In other study [54], carried out in the same model of $\mathrm{PH}$, showed that $2 \%$ baicalin solution downregulated the p38 mitogen-activated protein kinase MAPK/MMP9 pathway and expression levels of MMP-9. Huang et al. [51] observed additionally that baicalin $(60 \mathrm{mg} / \mathrm{kg}$ i.p.) attenuated chronic hypoxia-induced $\mathrm{PH}$ via adenosine A2A receptor-induced SDF-1/CXCR4/PI3K/AKT signaling. Liu et al. [55] investigated the effects of baicalin<smiles>O=C(O)[C@H]1O[C@@H](Oc2cc3oc(-c4ccccc4)cc(=O)c3c(O)c2O)C(O)[C@@H](O)C1O</smiles>

Figure 2a<smiles>O=c1cc(-c2ccccc2)oc2cc(O)c(O)c(O)c12</smiles>

Figure 2b

Chemical structure of baicalein (aglycon of baicalin) (ISIS Draw) 
at $30 \mathrm{mg} / \mathrm{kg}$ i.p. (daily dose) on the synthesis of collagen I in rats with $\mathrm{PH}$ caused by hypoxia. The found that baicalin significantly reduced: pulmonary artery pressure, the remodeling of the pulmonary artery under hypoxic conditions, the synthesis of collagen I in pulmonary arteries. Zhang et al. [57] showed that baicalin at dose $100 \mathrm{mg} / \mathrm{kg}$ i.p. (once daily for 14 days) reversed in vivo and in vitro the reduction of $\mathrm{p} 27$ caused by hypoxia and baicalin elevated AKT/protein kinase $B$ phosphorylation p-AKT. In this study it was observed that baicalin could effectively attenuate right ventricular systolic pressures and hypoxia-induced $\mathrm{PH}$. On the other hand, studies in rats with renovascular hypertension showed that baicalin $(2 \mathrm{ml}$ of $100 \mathrm{mg} / \mathrm{kg}$ baicalin i.p. for 4 weeks once a day) has no significant antihypertensive effect [52]. Baicalein (aglycon of baicalin) protected against hypertension associated with diabetes and showed decrease of vascular deleterious effects associated with both insulin deficiency (ID) and insulin resistance (IR) models. El-Bassossy et al. [56] carried out study of the potential protective effect of baicalein $(100 \mathrm{mg} / \mathrm{kg} /$ day $)$ against the hypertensive and harmful vascular effects of streptozotocin induced ID and IR caused by fructose in rats. In this study baicalein abrogated the elevation in blood pressure, and reduced the level of advanced glycation end products in both diabetic models, diminished the collagen deposition within aorta, caused a decrease in circulating serum level of TNF- $\alpha$, and prevented the activation of the NF- $\mathrm{NB}$ in aorta.

\section{Influence in pregnancy}

So far, only one study on the effect of baicalin in preeclampsia (PE) has been carried out. Wang et al. [67] pointed to the protective role of baicalin during injury of liver and kidney caused by $\mathrm{PE}$ in rat model. Baicalin were treated pregnant rats with PE in tree following doses: 50, 100, and $150 \mathrm{mg} / \mathrm{kg} /$ day, which were given by the intraperitoneal injection for 20 days. Results showed that apoptosis of liver or kidney cells were gradually down-regulated after application of baicalin at doses of $50 \mathrm{mg} / \mathrm{kg}$ and $100 \mathrm{mg} / \mathrm{kg}$. Moreover, expression of protein caspase 9 (indicator for apoptosis) diminished in live after middle dosages of baicalin, and the expression of XIAP (X-linked inhibitor of apoptosis protein) and bcl-2 (B-cell lymphoma 2) were diminished by different doses of baicalin. Additionally, it was indicated that baicalin leads to reversing the apoptotic processes in trophoblast in the placenta tissue of rats and ameliorating the ultrastructure of mitochondria by its down regulation of caspase- 9 expression. Other study showed that baicalin promoted embryo adhesion and implantation by upregulating of marker of the endometrial receptivity (fucosyltransferase IV) both in human endometrial cells and endometrium of mouse during the period of implantation [68]. Chen et al. [69] observed that baicalin $(40 \mathrm{mg} / \mathrm{kg}$, p.o.) decreased levels of the estradiol on 4-8 days of pregnancy and increased levels of the progesterone at 3-8 days of pregnancy. Analysis of results allowed to conclude that baicalin possessed tocolytic properties ameliorating the environment of the endometrial tissue for the implantation of the blastocyst. Previously, it was revealed that baicalin showed better anti-abortive effect in comparison with baicalein and wogonin [70]. This activity of baicalin was confirmed by Wang et al. [71] which showed protective effects of baicalin on decidua cells of pregnant mice abortion caused by LPS, and anti-abortive activity of baicalin was observed by Ma et al. [72] in bromocriptine-treated pregnant mice. On basis of these results it can be concluded that baicalin is safe and may exert beneficial effect on animals during gestation.

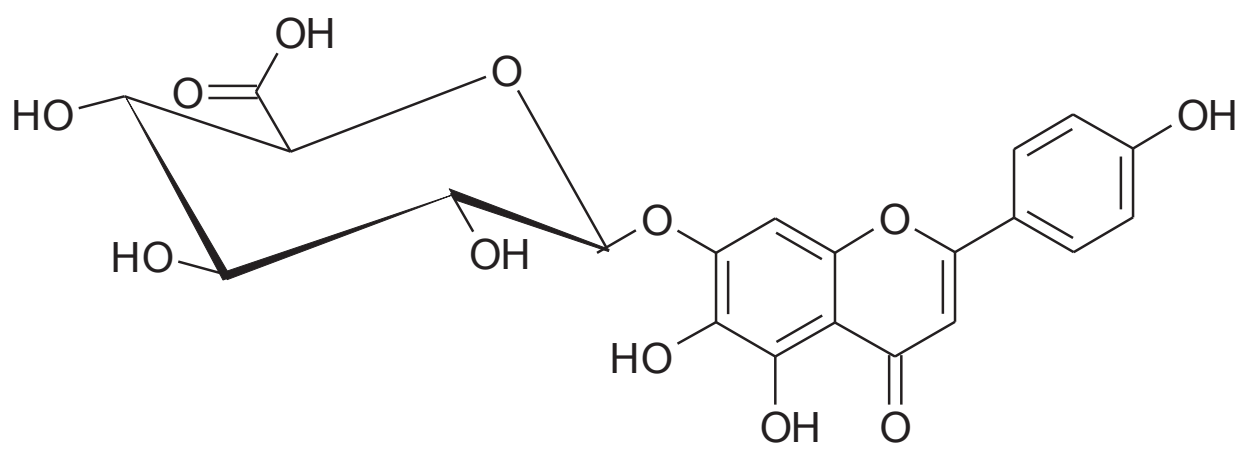

Figure 3

Chemical structure of scutellarin (ISIS Draw) 
<smiles>O=c1cc(-c2ccc(O)cc2)oc2cc(O)cc(O)c12</smiles>

Figure 4

Chemical structure of chrysin (ISIS Draw)

\section{SCUTELLARIN}

\section{Natural source and pharmacological profile}

Scutellarin (4,5,6-trihydroxy flavonoid-7-glucuronide or scutellarein-7-O-glucuronide) occurs in aerial parts (leaves and flowers) of Scutellaria baicalensis Georgi [3], Scutellaria galericulata L. [4], and Erigeron breviscapus (Vant.) Hand.-Mazz [73, 35]. It was revealed that Scutellaria has many activities such as cardioprotective [74], vasoprotective $[35,75]$, anti-oxidative, anti-inflammatory, vascular relaxative, anti-platelet and anti-coagulative [76]. Many studies revealed neuroprotective effects of scutellarin in various in vivo models [76-80]. Moreover, scutellarin improved microcirculation, diminished blood viscosity, showed antihypertensive effect in cerebrovascular diseases $[75,81,82]$ and has been successfully used in clinics for treatment of ischaemic diseases in China [83].

\section{In vitro and ex vivo studies related to hypertension Vasodilatation, vasoprotection}

Recently, Mo et al. [73] performed complex studies of scutellarin activity in various models in vitro. Their results showed that various concentrations of scutellarin used to estimation of antioxidative properties (total antioxidant capacity - TAC, 2,2-diphenyl-1picrylhydrazyl - DPPH, superoxide anion, and hydroxyl radical) scavenged all types of radicals in a dose-dependent manner, value of $\mathrm{EC}_{50}$ in scavenging hydroxyl radical was $37.11 \mu \mathrm{M}$. Scutellarin normalized the changes in expression of mRNA SOD1 (superoxide dismutase 1), and mRNA Nox4 (NADPH oxidase 4) caused by $\mathrm{H}_{2} \mathrm{O}_{2}$ in a dose-dependent manner. Furthermore, study on influence of scutellarin on human umbilical vein endothelial cells showed that scutellarin at a concentration of $400 \mu \mathrm{M}$ reduced the proliferation of these cells for $48 \mathrm{~h}$. Moreover, it was observed that scutellarin alone did not induce relaxation in ring of aorta of rabbits. Previously, study [75] carried out in isolated rat coronary artery rings showed the vasoprotective properties of scutellarin $(10-1,000 \mu \mathrm{mol} / \mathrm{l})$ against endothelial dysfunction induced by hypertension. Moreover, scutellarin induced coronary artery vasodilation in an endothelium and protected impairment caused by hypertension by activation of protein kinase signaling pathway. In other study it was showed that scutellarin caused relaxation in endothelium-intact depending on the dose [84]. In cultured human cardiac microvascular endothelial cells, this flavonoid ( 1 and $10 \mu \mathrm{M}$ ) protected cell viability in dose dependent manner and increased expression of PKG-I $\alpha$ [83].

\section{ACE inhibitory activities}

Wang et al. [35] showed the $\mathrm{IC}_{50}$ values of scutellarin against ACE in vitro is $48.13 \mu \mathrm{M}$, and it was concluded by authors that this flavonoid has a potent ACE inhibiting activity. Further studies were carried out by the same authors who applied AutoDock software and it was shown, using docking simulation, that ACE is the specific target of this flavonoid glycoside.

\section{In vivo studies related to the various models of hypertension}

Scutellarin ( $5 \mathrm{mg} / \mathrm{kg}$ and $20 \mathrm{mg} / \mathrm{kg}$ per day) significantly lowered systolic blood pressure in model of hypertensive rats (hypertension was induced using a 2-kidney, 2-clip method - 2K2C) [81]. It suppressed also the expression of Toll-like receptor 4 (TLR4) induced by hypertension and reduced hypertensionmediated induction of the inflammatory response by decrease the expression of proinflammatory mediators such as: NF- $\kappa$ B, TNF- $\alpha$, IL- $1 \beta$, and IL-18. On 
the basis of results it was concluded that scutellarin may be use as a potential therapeutic agent in diseases associated with hypertension [81]. In other study [83], scutellarin (45 and $90 \mathrm{mg} / \mathrm{kg}$, i.v.) significantly diminished ischemic size in myocardial ischemia reperfusion rat model. Other complex study [35] was performed in rats with permanent middle cerebral artery occlusion. Results showed that scutellarin dose-dependently (25, and 50, and $100 \mathrm{mg} / \mathrm{kg}$ p.o.) reduced of activity of angiotensin-converting enzyme (ACE) and the mRNA expression of receptor AT1 and ACE, and inflammatory mediators such as TNF- $\alpha$, IL- 6 , and IL- $1 \beta$. levels of these targets and angiotensin II were decreased.

\section{Influence during pregnancy}

In recent years studies on the impact of scutellarin during pregnancy in animals have not been published. Previously, acute and subacute toxicity studies in rodents showed that scutellarin has a sufficient margin of safety for therapeutic use [85].

\section{CHRYSIN}

\section{Natural source and pharmacological profile}

Chrysin (5,7-dihydroxyflavone) is a flavonoid occurring in many plants, honey, and propolis. According to review of Shang et al. [7], chrysin was identified in various plant of Scutellaria (Lamiace$a e$ ), such as: S. amoena C. H. Wright, S. baicalensis Georgi, S. linearis Benth., S. viscidula Bunge, S. strigillosa Hemsley, S. discolor Colebr. [5]. Moreover, chrysin was marked in herbs of Scutellaria galericulata L. [4], and Passilora caerulea L. [86, 87]. Chrysin showed various pharmacological effects, such as anti-inflammatory [88], antioxidant [89], and antihypertensive activity $[86,90,91,95]$, neuroprotective [86], anticancer properties [86], possessed protective effects against toxic agents [92], and many others [86].

\section{In vitro and ex vivo studies related to the causes of hypertension Vasodilatation, vasoprotection}

In vitro study using primary human umbilical vein endothelial cells revealed that chrysin inhibited endothelial inflammation via the NF- $\kappa \mathrm{B}$ signaling pathway because it can decrease level of pro-inflammatory factors [93]. Study performed in aortic rings showed that chrysin at concentration $10 \mu \mathrm{M}$ stimulated release of nitric oxide from endothelial cells and lead to aortic relaxation via increasing of cGMP concentration in cells [94]. Additionally, chrysin (1, 10, and $100 \mu \mathrm{M}$ ) highly diminished proliferation in the cultured pulmonary artery smooth muscle cells. Furthermore, this dihydroxyflavone reduced the upregulated mRNA and expressions of collagen I and collagen III after hypoxia and chrysin could inhibit expression of mRNA NOX4. Next observation showed, that in this cell culture reduced generation of reactive oxygen species and content of malondialdehyde [91].

\section{In vivo studies related to the various models of hypertension}

Beneficial effect of chrysin was observed in pulmonary hypertensive rats after hypoxia [91]. In this study showed that treatment with chrysin at doses 50 or $100 \mathrm{mg} / \mathrm{kg} / \mathrm{day}$ (s.c.) for 4 weeks significantly ameliorated homodynamic and cardiovascular remodeling, alleviated hypertrophy of the right ventricle and pulmonary arteries. Chrysin decreased also proliferation of smooth muscle cells in the vascular media of small pulmonary arteries [91]. Veerappan and Malarvili [90] observed that chrysin ( $25 \mathrm{mg} / \mathrm{kg} /$ day for 4 weeks, p.o.) administered to rats with hypertension caused by N-nitro-Larginine methyl ester showed antihypertensive effect throughout the following mechanism of action such as: reduction in functions of left ventricular, oxidative stress in cardiac tissue and level of angiotensin II in plasma, and increasing of hexooxygenase in cardiac tissue, concentration of cGMP and a prevention of plasma nitric oxide loss. Other study was carried out to estimation of effects of chrysin supplementation on blood pressure of rats fed a high-fat and highsucrose diet in comparison with quercetin [95]. Results showed that chrysin suppressed the elevation of blood pressure in normotensive rats and exerted an antihypertensive effect similar to quercetin.

\section{Influence during pregnancy}

There is a lack of scientific evidence on the use of chrysin during pregnancy. Chrysin did not showed activity using ovarian aromatase [96] or in endometrial cells [97]. 


\section{CONCLUSION AND SUMMARY}

In summary, the review of current studies shows that apigenin, baicalin, and also chrysin or scutellarin possess antihypertensive activities via various mechanisms of action. Apigenin and baicalin are the most investigated in this field and they showed mainly vasodilatative properties and protective activities for endothelial cells. So far, data on their effects in pregnancy-induced hypertension are generally (except baicalin) unavailable. Therefore, it would be interesting to conduct research on apigenin, baicalin, chrysin, scutellarin as a new potential complex plant-origin drugs in the treatment of hypertension induced by pregnancy in animal models.

Ethical approval: The conducted research is not related to either human or animal use.

\section{Conflict of interest: Authors declare no conflict of} interest.

\section{ACKNOWLEDGMENTS}

This research was carried out within the framework of a research project No. 2017/25/B/NZ7/02741 financed by the National Science Center, Poland. Authors thank to dr Jacek Kujawski from Dep. of Organic Chemistry at Poznań University of Medical Sciences for helpful assistance in drawing of flavonoids structures using ISIS Draw Software (for academic and non-commercial use; https://accelrysdraw.de.softonic.com).

\section{REFERENCES}

1. Fairbairn J W (ed.). The pharmacology of plant phenolics. Academic Press INC. New York 1959.

2. Ożarowski M, Mikołajczak PŁ, Kujawski R, Wielgus K, Klejewski A, Wolski $\mathrm{H}$ et al. Pharmacological effect of quercetin in hypertension and its potential application in pregnancy-induced hypertension: review of in vitro, in vivo, and clinical studies. Evid Based Complement Alternat Med 2018:7421489. doi: http://dx.doi. org/10.1155/2018/7421489

3. Zhao Q, Chen XY, Martin C. Scutellaria baicalensis, the golden herb from the garden of Chinese medicinal plants. Sci Bull 2016; 61(18):1391-
1398. doi: http://dx.doi.org/10.1007/s11434-0161136-5

4. Kosakowska O, Bączek K, Przybył JL, PióroJabrucka E, Węglarz Z. Chemical variability of common skullcap (Scutellaria galericulata L.) wild growing in the area of eastern Poland. Herba Pol 2016; 62(3):7-19. doi: http://dx.doi. org/10.1515/hepo-2016-0013

5. Laishram S, Moirangthem DS, Borah JC, Pal BC, Suman P, Gupta SK et al. Chrysin rich Scutellaria discolor Colebr. induces cervical cancer cell death via the induction of cell cycle arrest and caspasedependent apoptosis. Life Sci 2015; 143:105-113. doi: http://dx.doi.org/10.1016/j.lfs.2015.10.035

6. Lin W, Liu S, Wu B. Structural identification of chemical constituents from Scutellaria baicalensis by HPLC-ESI-MS/MS and NMR spectroscopy. Asian J Chem 2013; 25(7):3799-3805. doi: http:// dx.doi.org/10.14233/ajchem.2013.13788

7. Shang X, He X, He X, Li M, Zhang R, Fan P et al. The genus Scutellaria an ethnopharmacological and phytochemical review. J Ethnopharmacol 2010; 128:279-313. doi: http://dx.doi. org/10.1016/j.jep.2010.01.006

8. Wang Y, Jia Y, Yang X, Liang B, Gao H, Yang T. A potential role of baicalin to inhibit apoptosis and protect against acute liver and kidney injury in rat preeclampsia model. Biomed Pharmacother 2018; 108:1546-1552. doi: http://dx.doi. org/10.1016/j.biopha.2018.09.107

9. Luanni VB, Ota E, Togoobaatar G, Rintaro M, Joao PS. Risk factors of pre-eclampsia/eclampsia and its adverse outcomes in low- and middle income countries: a WHO secondary analysis. PLoS ONE 2014; 9(3):e91198. doi: http://dx.doi. org/10.1371/journal.pone.0091198

10. Fauci AS, Braunwald E, Kasper DL. Disorders of intermediary metabolism. In: Fauci AS, Braunwald E, Kasper DL (eds.). Harrison's Principles of Internal Medicine. $17^{\text {th }}$ ed. New York 2008:24262429.

11. Meyer H, Bolarinwa A, Wolfram G, Linseisen J. Bioavailability of apigenin from apiin-rich parsley in humans. Ann Nutr Metab 2006; 50:167172. doi: http://dx.doi.org/10.1159/000090736 
12. Haghi G, Hatami A, Safaei A, Mehran M. Analysis of phenolic compounds in Matricaria chamomilla and its extracts by UPLC-UV. Res Pharm Sci 2014; 9(1):31-37.

13. Tashakori-Sabzevar F, Marjan Razavi B, Imenshahidi M, Daneshmandi M, Fatehi H, Entezari Sarkarizi Y et al. Evaluation of mechanism for antihypertensive and vasorelaxant effects of hexanic and hydroalcoholic extracts of celery seed in normotensive and hypertensive rats. Rev Bras Farmacogn 2016; 26:619-626. doi: http://dx.doi. org/10.1016/j.bjp.2016.05.012

14. Zhou X, Wang F, Zhou R, Song X, Xie M. Apigenin: A current review on its beneficial biological activities. J Food Biochem 2017; 41:e12376. doi: http://dx.doi.org/10.1111/jfbc.12376

15. Wang X, Ouyang YY, Liu J, Zhao G. Flavonoid intake and risk of CVD: a systematic review and meta-analysis of prospective cohort studies. Br J Nutr 2014; 111(1):1-11. doi: http://dx.doi. org/10.1017/S000711451300278X

16. Ali F, Rahul, Naz F, Jyoti S, Siddique YH. Health functionality of apigenin: a review. Int J Food Prop 2017; 20(6):1197-38. doi: http://dx.doi.org/ 10.1080/10942912.2016.1207188

17. Gupta S, Afaq F, Mukhtar H. Selective growthinhibitory, cell-cycle deregulatory and apoptotic response of apigenin in normal versus human prostate carcinoma cells. Biochem Biophys Res Commun 2001; 87:914-920. doi: http://dx.doi. org/10.1006/bbrc.2001.5672

18. Ko FN, Huang TF, Teng CM. Vasodilatory action mechanisms of apigenin isolated from Apium graveolens in rat thoracic aorta. Biochim Biophys Acta 1991; 1115(1):69-74. doi: http://dx.doi. org/10.1016/0304-4165(91)90013-7

19. Jin BH, Qian LB, Chen S, Li J, Wang HP, Bruce IC et al. Apigenin protects endothelium-dependent relaxation of rat aorta against oxidative stress. Eur J Pharmacol 2009; 616(1-3):200-205. doi: http://dx.doi.org/10.1016/j.ejphar.2009.06.020

20. Senejoux F, Demougeot C, Kerram P, Aisa HA, Berthelot A, Bévalot F et al. Bioassay-guided isolation of vasorelaxant compounds from Ziziphora clinopodioides Lam. (Lamiaceae). Fitoterapia. 2012; 83(2):377-82. doi: http:// dx.doi.org/10.1016/j.fitote.2011.11.023
21. Tang J, Zhang Y, Hartman TG, Rosen RT, Ho CT. Free and glycosidically bound volatile compounds in fresh celery (Apium graveolens L.). J Agric Food Chem 1990;38:1937-1940.

22. Vargas F, Romecín P, García-Guillén AI, Wangesteen R, Vargas-Tendero P, Paredes MD et al. Flavonoids in kidney health and disease. Front Physiol 2018; 24:394. doi: http://dx.doi. org/10.3390/nu10081107

23. Paredes MD, Romecín P, Atucha NM, O’Valle F, Castillo J, Ortiz MC et al. Beneficial effects of different flavonoids on vascular and renal function in L-NAME hypertensive rats. Nutrients 2018; 10:484. doi: http://dx.doi.org/10.3390/ nu10040484

24. Sui H, Yu Q, Zhi Y, Geng G, Liu H, Xu H. Effects of apigenin on the expression of angiotensinconverting enzyme 2 in kidney in spontaneously hypertensive rats. Wei Sheng Yan Jiu 2010; 39(6):693-6:700.

25. Soñanez-Organis JG, Godoy-Lugo JA, Hernández-Palomares ML, Rodríguez-Martínez D, Rosas-Rodríguez JA, González-Ochoa G et al. HIF- $1 \alpha$ and PPAR $\gamma$ during physiological cardiac hypertrophy induced by pregnancy: Transcriptional activities and effects on target genes. Gene 2016; 591(2):376-81. doi: http:// dx.doi.org/10.1016/j.gene.2016.06.025

26. Zhu ZY, Gao T, Huang Y, Xue J, Xie ML. Apigenin ameliorates hypertension-induced cardiac hypertrophy and down-regulates cardiac hypoxia inducible factor-l $\alpha$ in rats. Food Funct 2016; 7(4):1992-1998. doi: http://dx.doi.org/10.1039/ c5fo01464f

27. Wei X, Gao P, Pu Y, Li Q, Yang T, Zhang H et al. Activation of TRPV4 by dietary apigenin antagonizes renal fibrosis in deoxycorticosterone acetate (DOCA)-salt-induced hypertension. Clin Sci (Lond) 2017; 131(7):567-581. doi: http://dx.doi. org/10.1042/CS20160780

28. Zhang K, Song W, Li D, Jin X. Apigenin in the regulation of cholesterol metabolism and protection of blood vessels. Exp Ther Med 2017; 13(5):1719-1724. doi: http://dx.doi.org/10.3892/ etm.2017.4165

29. Alig SK, Stampnik Y, Pircher J, Rotter R, Gaitzsch E, Ribeiro A et al. The tyrosine phosphatase 
SHP-1 regulates hypoxia inducible factor- $1 \alpha$ $($ HIF-1 $\alpha)$ protein levels in endothelial cells under hypoxia. PLoS One. 2015;10:e0121113. doi: http://doi.org/10.1371/journal.pone.0121113

30. Zargaran A, Borhani-Haghighi A, Faridi P, Daneshamouz S, Kordafshari G, Mohagheghzadeh A. Potential effect and mechanism of action of topical chamomile (Matricaria chammomila L.) oil on migraine headache: a medical hypothesis. Med Hypotheses 2014; 83:566-569. doi: http:// dx.doi.org/10.1016/j.mehy.2014.08.023

31. Lim R, Barker G, Wall CA, Lappas M. Dietary phytophenols curcumin, naringenin and apigenin reduce infection-induced inflammatory and contractile pathways in human placenta, foetal membranes and myometrium. Mol Hum Reprod 2013; 19(7):451-62. doi: http://dx.doi. org/10.1093/molehr/gat015

32. Al-Gubory KH, Fowler PA, Garrel C. The roles of cellular reactive oxygen species, oxidative stress and antioxidants in pregnancy outcomes. Int $\mathrm{J} \mathrm{Bi}$ ochem Cell Biol 2010; 42:1634-1650. doi: http:// dx.doi.org/10.1016/j.biocel.2010.06.001

33. Lappas M, Hiden U, Desoye G, Froehlich J, Hauguel-de Mouzon S, Jawerbaum A. The role of oxidative stress in the pathophysiology of gestational diabetes mellitus. Antioxid Redox Signal 2011; 15:3061-3100. doi: http://dx.doi.org/10.1089/ ars. 2010.3765

34. Woods JR Jr. Reactive oxygen species and preterm premature rupture of membranes - a review. Placenta 2001; 22(Suppl. A):S38-S44. doi: http://dx.doi.org/10.1053/plac.2001.0638

35. Chai M, Barker G, Menon R, Lappas M. Increased oxidative stress in human fetal membranes overlying the cervix from term nonlabouring and post labour deliveries. Placenta 2012; 33(8):604-610. doi: http://dx.doi. org/10.1016/j.placenta.2012.04.014

36. Awad JA, Roberts LJ II, Burk RF, Morrow JD. Isoprostanes - prostaglandin - like compounds formed in vivo independently of cyclooxygenase: use as clinical indicators of oxidant damage. Gastroenterol Clin North Am 1996; 25:409-427.

37. Nicholas C, Batra S, Vargo MA, Voss OH, Gavrilin MA, Wewers MD et al. Apigenin blocks lipopol- ysaccharide-induced lethality in vivo and proinflammatory cytokines expression by inactivating $\mathrm{NF}$ - kappaB through the suppression of $\mathrm{p} 65$ phosphorylation. J Immunol 2007; 179:7121-7127. doi: http://dx.doi.org/10.4049/jimmunol.179.10.7121

38. Chandler D, Woldu A, Rahmadi A, Shanmugam $\mathrm{K}$, Steiner N, Wright $\mathrm{E}$ et al. Effects of plant-derived polyphenols on TNF -alpha and nitric oxide production induced by advanced glycation endproducts. Mol Nutr Food Res 2010; 54(Suppl. 2):S141-S150. doi: http://dx.doi.org/10.1002/ mnfr.200900504

39. Chen G, Zhang H, Ye J. Determination of baicalein, baicalin and quercetin in Scutellariae radix and its preparations by capillary electrophoresis with electrochemical detection. Talanta 2000; 53:471-479.

40. Tuan PA, Kim YS, Kim Y, Thwe AA, Li X, Park $\mathrm{CH}$ et al. Molecular characterization of flavonoid biosynthetic genes and accumulation of baicalin, baicalein, and wogonin in plant and hairy root of Scutellaria lateriflora. Saudi J Biol Sci 2018; 25(8):1639-1647. doi: http://dx.doi.org/10.1016/j. sjbs.2016.08.011

41. Wang Y, Wei Z, Zhang J, Wang X. Electrochemical determination of baicalein, baicalin and quercetin in Scutellaria barbata. Int J Electrochem Sci 2016; 11:8323-8331. doi: http://dx.doi. org/10.20964/2016.10.03

42. Moghaddam E, Teoh BT, Sam SS, Lani R, Hassandarvish $\mathrm{P}$, Chik $\mathrm{Z}$ et al. Baicalin, a metabolite of baicalein with antiviral activity against dengue virus. Sci Rep 2014; 4:5452. doi: http://dx.doi. org/10.1038/srep05452

43. Slachmuylders L, Van Acker H, Brackman G, Sass A, Van Nieuwerburgh F, Coenye T. Elucidation of the mechanism behind the potentiating activity of baicalin against Burkholderia cenocepacia biofilms. PLoS ONE 2018; 13(1): e0190533. doi: http://dx.doi.org/10.1371/journal.pone.0190533

44. Sowndhararajan K, Deepa P, Kim M, Park SJ, Kim S. Neuroprotective and cognitive enhancement potentials of baicalin: A review. Brain Sci 2018; 8(6):104. http://dx.doi.org/10.3390/brainsci8060104

45. Liang W, Huang X, Chen W. The effects of baica- 
lin and baicalein on cerebral ischemia: A review. Aging Dis 2017; 8(6):850-867. doi: http://dx.doi. org/ 10.14336/AD.2017.0829

46. Luan Y, Chao S, Ju ZY, Wang J, Xue X, Qi TG et al. Therapeutic effects of baicalin on monocrotaline-induced pulmonary arterial hypertension by inhibiting inflammatory response. Int Immunopharmacol 2015; 26(1):188-193. doi: http://dx.doi. org/10.1016/j.intimp.2015.01.009

47. Donald G, Hertzer K, Eibl G. Baicalein - an intriguing therapeutic phytochemical in pancreatic cancer. Curr Drug Targets 2012; 13(14):1772-1776.

48. Li-Weber M. New therapeutic aspects of flavones: the anticancer properties of Scutellaria and its main active constituents wogonin, baicalein and baicalin. Cancer Treat Rev 2009; 35(1):57-68. doi: http://dx.doi.org/10.1016/j.ctrv.2008.09.005

49. He P, Wu Y, Shun J, Liang Y, Cheng M, Wang $\mathrm{Y}$. Baicalin ameliorates liver injury induced by chronic plus binge ethanol feeding by modulating oxidative stress and inflammation via CYP2E1 and NRF2 in mice. Oxid Med Cell Longev 2017; 4820414. doi: http://dx.doi. org/10.1155/2017/4820414

50. Zhang Y, Liao P, Zhu M, Li W, Hu D, Guan S et al. Baicalin attenuates cardiac dysfunction and myocardial remodeling in a chronic pressure-overload mice model. Cell Physiol Biochem 2017; 41(3):849-864. doi: http://dx.doi. org/10.1159/000459708

51. Huang X, Wu P, Huang F, Xu M, Chen M, Huang $\mathrm{K}$ et al. Baicalin attenuates chronic hypoxia-induced pulmonary hypertension via adenosine $\mathrm{A}_{2 \mathrm{~A}}$ receptor-induced SDF-1/CXCR4/PI3K/AKT signaling. J Biomed Sci 2017; 24(1):52. doi: http:// dx.doi.org/10.1186/s12929-017-0359-3

52. Dai H, Zhang X, Yang Z, Li J, Zheng J. Effects of baicalin on blood pressure and left ventricular remodeling in rats with renovascular hypertension. Med Sci Monit 2017; 23:2939-2948. doi: http:// dx.doi.org/10.12659/MSM.902536

53. Chen Z, Wang Q. Activation of PPAR $y$ by baicalin attenuates pulmonary hypertension in an infant rat model by suppressing HMGB1/RAGE signaling. FEBS Open Bio 2017; 7(4):477-484 doi: http://dx.doi.org/10.1002/2211-5463
54. Yan S, Wang Y, Liu P, Chen A, Chen M, Yao D et al. Baicalin attenuates hypoxia-induced pulmonary arterial hypertension to improve hypoxic cor pulmonale by reducing the activity of the p38 MAPK signaling pathway and MMP-9. Evid Based Complement Alternat Med 2016; vol. 2016. doi: http:// dx.doi.org/10.1155/2016/2546402

55. Liu P, Yan S, Chen M, Chen A, Yao D, Xu X et al. Effects of baicalin on collagen I and collagen III expression in pulmonary arteries of rats with hypoxic pulmonary hypertension. Int $\mathrm{J}$ Mol Med 2015; 35(4):901-988. doi: http://dx.doi. org/10.3892/ijmm.2015.2110

56. El-Bassossy HM, Hassan NA, Mahmoud MF, Fahmy A. Baicalein protects against hypertension associated with diabetes: effect on vascular reactivity and stiffness. Phytomedicine 2014; 21(12):1742-1745. doi: http://dx.doi. org/10.1016/j.phymed.2014.08.012

57. Zhang L, Pu Z, Wang J, Zhang Z, Hu D, Wang J. Baicalin inhibits hypoxia-induced pulmonary artery smooth muscle cell proliferation via the AKT/HIF- $1 \alpha /$ p27-associated pathway. Int J Mol Sci 2014; 15(5):8153-8168. doi: http://dx.doi. org/10.3390/ijms15058153

58. Deng YF, Aluko RE, Jin Q, Zhang Y, Yuan LJ. Inhibitory activities of baicalin against renin and angiotensin-converting enzyme. Pharm Biol 2012; 50:401-406. doi: http://dx.doi.org/10.3109/ 13880209.2011.608076

59. Lin YL, Dai ZK, Lin RJ, Chu KS, Chen IJ, Wu JR et al. Baicalin, a flavonoid from Scutellaria baicalensis Georgi, activates large-conductance $\mathrm{Ca}^{2+}$-activated $\mathrm{K}^{+}$channels via cyclic nucleotidedependent protein kinases in mesenteric artery. Phytomedicine 2010; 17:760-770. doi: http:// dx.doi.org/10.1016/j.phymed.2010.01.003

60. Chang CP, Huang WT, Cheng BC, Hsu CC, Lin MT. The flavonoid baicalin protects against cerebrovascular dysfunction and brain inflammation in experimental heatstroke. Neuropharmacol 2007; 52(3):1024-1033. doi: http://dx.doi. org/10.1016/j.neuropharm.2006.10.018

61. Lee W, Ku SK, Bae JS. Antiplatelet, anticoagulant, and profibrinolytic activities of baicalin. Arch Pharm Res 2015; 38:893-903. doi: http://dx.doi. org/10.1007/s12272-014-0410-9 
62. Dong SJ, Zhong YQ, Lu WT, Li GH, Jiang HL, Mao B. Baicalin inhibits lipopolysaccharideinduced inflammation through signaling NF- $\kappa \mathrm{B}$ pathway in HBE16 airway epithelial cells. Inflammation 2015; 38(4):1493-501. doi: http://dx.doi. org/10.1007/s10753-015-0124-2

63. Shou X, Wang B, Zhou R, Wang L, Ren A, Xin $S$ et al. Baicalin suppresses hypoxia-reoxygenation-induced arterial endothelial cell apoptosis via suppressing $\mathrm{PKC} / \mathrm{p} 53$ Signaling. Med Sci Monit 2017; 23:6057-6063. doi: http://dx.doi. org/10.12659/MSM.907989

64. Yang X, Zhang Q, Gao Z, Yu C, Zhang L. Baicalin alleviates IL- $1 \beta$-induced inflammatory injury via down-regulating miR-126 in chondrocytes. Biomed Pharmacother 2018; 99:184-190. doi: http://dx.doi.org/10.1016/j.biopha.2018.01.041

65. Li M, Wang Y, Li X, Li J, Wang B. Protection of compatibility of saikosapon $\mathrm{d}$ and baicalin on carbon tetrachloride injured L-02 cells based on TLR4-NFkB signaling pathway. Medicinal Plant, 2018; 9(2):61-64. doi: http://dx.doi. org/10.19600/j.cnki.issn2152-3924.2018.02.015

66. Wu T, Liu T, Xing L, Ji G. Baicalin and puerarin reverse epithelial-mesenchymal transition via the TGF- $\beta 1 /$ Smad 3 pathway in vitro. Exp Ther Med 2018; 16(3):1968-1974. doi: http://dx.doi. org/10.3892/etm.2018.6400

67. Wang Q, Xu H, Zhao X. Baicalin inhibits human cervical cancer cells by suppressing protein kinase $\mathrm{C} /$ signal transducer and activator of transcription (PKC/STAT3) signaling pathway. Med Sci Monit 2018; 24:1955-1961. doi: http://dx.doi. org/10.12659/MSM.909640

68. Zhang YM, Zhang YY, Bulbul A, Shan X, Wang $\mathrm{XQ}$, Yan Q. Baicalin promotes embryo adhesion and implantation by upregulating fucosyltransferase IV (FUT4) via Wnt/beta-catenin signaling pathway. 2015; 589(11):1225-33. doi: http:// dx.doi.org/10.1016/j.febslet.2015.04.011

69. Chen JG, Chen T, Ding Y, Han L, Zhou FY, Chen WZ et al. Baicalin can attenuate the inhibitory effects of mifepristone on Wnt pathway during peri-implantation period in mice. J Steroid Biochem Mol Biol 2015; 149:11-6. doi: http://dx.doi. org/10.1016/j.jsbmb.2014.11.023
70. Ma AT, Zhong XH, Meng LG, Ni YD, Xu L, Chen YX. Effects of monomer ingredients of Scutellaria baicalensis Georgi on the maternalfetal immunity in pregnant mice. Chin J Vet Sci 2007; 27:412-415.

71. Wang X, Zhao Y, Zhong X. Protective effects of baicalin on decidua cells of LPS-induced mice abortion. J Immunol Res 2014; 2014:859812. doi: http://dx.doi.org/10.1155/2014/859812

72. Ma AT, Zhong XH, Liu ZM, Shi WY, Du J, Zhai $\mathrm{XH}$ et al. Protective effects of baicalin against bromocriptine-induced abortion in mice. Am J Chin Med 2009; 37(1):85-95. doi: http://dx.doi. org/10.1142/S0192415X09006709

73. Mo J, Yang R, Li F, Zhang X, He B, Zhang Y et al. Scutellarin protects against vascular endothelial dysfunction and prevents atherosclerosis via antioxidation. Phytomedicine 2018; 42:66-74. doi: http://dx.doi.org/10.1016/j.phymed.2018.03.021

74. Huang H, Geng Q, Yao H, Shen Z, Wu Z, Miao X et al. Protective effect of scutellarin on myocardial infarction induced by isoprenaline in rats. Iran J Basic Med Sci 2018; 21(3):267-276. doi: http:// dx.doi.org/10.22038/ijbms.2018.26110.6415

75. Chen YJ, Wang L, Zhou GY, Yu XL, Zhang YH, $\mathrm{Hu} \mathrm{N}$ et al. Scutellarin attenuates endothelium-dependent vasodilation impairment induced by hypoxia reoxygenation, through regulating the PKG signaling pathway in rat coronary artery. Chin J Nat Med 2015; 13(4):0264-0273. doi: http://dx.doi. org/10.1016/S1875-5364(15)30013-3

76. Wang L, Ma Q. Clinical benefits and pharmacology of scutellarin: A comprehensive review. Pharmacol Ther 2018; 190:105-127. doi: http://dx.doi. org/10.1016/j.pharmthera.2018.05.006

77. Yuan Y, Fang M, Wu CY, Ling EA. Scutellarin as a potential therapeutic agent for microglia-mediated neuroinflammation in cerebral ischemia. Neuromol Med 2016; 18:264-273. doi: http://dx.doi. org/10.1007/s12017-016-8394-x

78. Fang M, Yuan Y, Lu J, Li HE, Zhao M, Ling EA et al. Scutellarin promotes microglia-mediated astrogliosis coupled with improved behavioral function in cerebral ischemia. Neurochem Int 2016;97:154-171. doi: http://dx.doi.org/10.1016/j. neuint.2016.04.007 
79. Fang M, Yuan Y, Rangarajan P, Lu J, Wu Y, Wang $\mathrm{H}$ et al. Scutellarin regulates microglia-mediated TNC1 astrocytic reaction and astrogliosis in cerebral ischemia in the adult rats. BMC Neurosci 2015; 16:84. doi: http://dx.doi.org/10.1186/ s12868-015-0219-6

80. Zhang HF, Hu XM, Wang LX, Xu SQ, Zeng FD. Protective effects of scutellarin against cerebral ischemia in rats: evidence for inhibition of the apoptosis-inducing factor pathway. Planta Medica 2009; 75(2):121-126. doi: http://dx.doi. org/10.1371/journal.pone.0146197

81. Chen X, Shi X, Zhang X, Lei H, Long S, Su H et al. Scutellarin attenuates hypertension-induced expression of brain toll-like receptor 4/Nuclear Factor Kappa B. Mediators Inflamm 2013; vol. 2013. doi: http://dx.doi.org/10.1155/2013/432623

82. Lin LL, Liu AJ, Liu JG, Yu XH, Qin LP, Su DF. Protective effects of scutellarin and breviscapine on brain and heart ischemia in rats. J Cardiovasc Pharmacol 2007; 50:327-332.

83. Li L, Li L, Chen C, Yang J, Li J, Hu N et al. Scutellarin's cardiovascular endothelium protective mechanism: important Role of PKG-Ia. PLoS ONE 2015; 10(10): e0139570. doi: http://dx.doi. org/10.1371/journal. pone.0139570

84. Pan Z, Feng T, Shan L, Cai B, Chu W, Niu H et al. Scutellarin-induced endothelium-independent relaxation in rat aorta. Phytother Res 2008; 22(11):1428-33. doi: http://dx.doi.org/10.1002/ ptr.2364

85. Li X, Wang L, Li Y, Bai L, Xue M. Acute and subacute toxicological evaluation of scutellarin in rodents. Regul Toxicol Pharmacol 2011; 60(1):106-11. doi: http://dx.doi.org/10.1016/j. yrtph.2011.02.013

86. Mani R, Natesan V. Chrysin: Sources, beneficial pharmacological activities, and molecular mechanism of action. Phytochem 2018;145:187-196. doi: http://dx.doi. org/10.1016/j.phytochem.2017.09.016

87. Ożarowski M, Piasecka A, Paszel-Jaworska A, Chaves DSA, Romaniuk A, Rybczynska $\mathrm{M}$ et al. Comparison of bioactive compounds content in leaf extracts of Passiflora incarnata, $P$. caerulea and $P$. alata and in vitro cytotoxic potential on leukemia cell lines. Rev Bras Farmacogn 2018; 28:179-191. doi: http://dx.doi.org/10.1016/j. bjp.2018.01.006

88. Ahad A, Ganai AA, Mujeeb M, Siddiqui WA. Chrysin, an anti-inflammatory molecule, abrogates renal dysfunction in type 2 diabetic rats. Toxicol Appl Pharmacol 2014; 279:1-7. doi: http://dx.doi.org/10.1016/j.taap.2014.05.007

89. Missassi G, Borges CS, Rosa JL, Silva PV, Martins AC, Barbosa $\mathrm{F}$ et al. Chrysin administration protects against oxidative damage in varicocele-induced adult rats. Oxid Med Cell Longev 2017; 2017:2172981. doi: http://dx.doi. org/10.1155/2017/2172981

90. Veerappan R, Malarvili T. Chrysin pretreatment improves angiotensin system, cGMP concentration in L-NAME induced hypertensive rats. Ind J Clin Biochem 2018. doi: http://dx.doi. org/10.1007/s12291-018-0761-y

91. Li XW, Wang XM, Li S, Yang JR. Effects of chry$\sin$ (5,7-dihydroxyflavone) on vascular remodeling in hypoxia-induced pulmonary hypertension in rats. Chinese Med 2015; 10(4):1-13. doi: http://dx.doi.org/10.1186/s13020-015-0032-2

92. Samarghandian S, Farkhondeh T, AzimiNezhad M. Protective effects of chrysin against drugs and toxic agents. Dose Response 2017; 15(2):1559325817711782. doi: http://dx.doi. org/10.1177/1559325817711782

93. Zhao S, Liang M, Wang Y, Hu J, Zhong Y, Li J et al. Chrysin suppresses vascular endothelial inflammation via inhibiting the NF- $\mathrm{KB}$ signaling pathway. J Cardiovasc Pharmacol Ther 2018:1074248418810809. doi: http://dx.doi. org/10.1177/1074248418810809

94. Villar IC, Vera R, Galisteo M, O’Valle F, Romero $\mathrm{M}$, Zarzuelo A et al. Endothelial nitric oxide production stimulated by the bioflavonoid chrysin in rat isolated aorta. Planta Med 2005; 71:829-834. doi: http://dx.doi.org/10.1055/s-2005-871296

95. Yamamoto Y. Effects of dietary chrysin supplementation on blood pressure and oxidative status of rats fed a high-fat high-sucrose diet. Food Sci Technol Res 2014; 20(2):295-300. doi: http:// dx.doi.org/10.3136/fstr.20.295 
96. Pelissero C, Lenczowski MJ, Chinzi D, Davail-Cuisset B, Sumpter JP, Fostier A. Effects of flavonoids on aromatase activity, an in vitro study. J Steroid Biochem Mol Biol 1996; 57(34):215-23.
97. Edmunds KM, Holloway AC, Crankshaw DJ, Agarwal SK, Foster WG. The effects of dietary phytoestrogens on aromatase activity in human endometrial stromal cells. Reprod Nutr Dev 2005; 45(6):709-20. doi: http://dx.doi. org/10.1051/rnd:2005055 